\title{
Avaliação dos impactos da transposição do Rio São Francisco
}

\author{
Impact Evaluation of the São Francisco River Transposition
}

\section{Isabel Cardlim de Resende \\ isabel_resende123@hotmail.com}

Aluna de graduação em bacharel em Ciências Biológicas, na PUC-Rio. Preocupada com a causa ambiental e estudante da fauna.

\section{Rafaela Rocha dos Santos rafaelars71@ hotmail.com}

Aluna de graduação em bacharel em Ciências Biológicas, na PUC-Rio. Preocupada com a causa ambiental e estudante da fauna.

\begin{abstract}
Resumo
A Transposição do Rio São Francisco objetiva levar água para regiões mais vulneráveis à seca no Nordeste do Brasil. Porém, esse projeto não visa o desenvolvimento sustentável. Sendo assim, o objetivo deste trabalho foi analisar a veracidade dos impactos citados no RIMA com base em pesquisas e análises já publicadas. Foi possível analisar 5 parâmetros, e assim concluímos que há a necessidade de se ter atenção aos impactos causados pelo projeto. Palavras-chave: desenvolvimento sustentável; análise de impactos; legislação ambiental.
\end{abstract}

\begin{abstract}
The São Francisco River Transposition has as objective take water to regions that are vulnerable to drought, in Brazil Northeast. However, this project does not aim for sustainable development. Thus, the present work aims to analyze the veracity of impacts cited on RIMA with base in researches and analyses already published. It was possible to analyze 5 parameters, and we concluded that there is a necessity to pay attention to the impacts that the project caused.
\end{abstract}

Keywords: sustentable development; impact analyses; ambiental legislation. 


\section{Introdução}

O Projeto de Integração do Rio São Francisco é um empreendimento hídrico que tem por objetivo levar água para regiões vulneráveis à seca, nos estados de Pernambuco, Paraíba, Rio Grande do Norte e Ceará (MDR, 2019). As famílias que vivem no semiárido Nordestino sofrem com as condições climáticas, passando por períodos de seca devido à irregularidade das chuvas, o que ameaça a vida na região (MARENGO et al., 2011). Como vivem da agricultura e pecuária, a falta de chuva impossibilita a produção de insumos para a subsistência (GOMES, 2001). Uma das soluções para esse problema seria o desvio de parte das águas do Rio São Francisco, ideia presente no discurso de autoridades desde 1875 (RIMA, 2004).

No ponto de vista da oferta hídrica, o Semiárido brasileiro pode ser dividido em Semiárido da bacia do São Francisco e Semiárido do Nordeste Setentrional; o primeiro

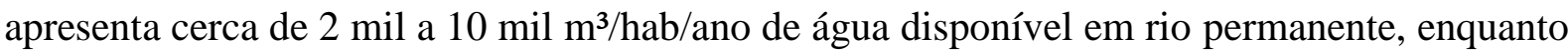
o segundo possui cerca de $400 \mathrm{~m}^{3} / \mathrm{hab} / \mathrm{ano}$ disponibilizados em açudes construídos em rios intermitentes e em aquíferos, havendo limitações da quantidade e qualidade de água (CASTRO, 2011). Devido a isso, o objetivo do projeto é integrar as águas do Rio São Francisco com as bacias hidrográficas do Nordeste Setentrional por meio de dois sistemas denominados Eixo Norte e Eixo Leste que captarão água do rio entre as barragens de Sobradinho e Itaparica (RIMA, 2004).

Entretanto, o projeto recebeu críticas e foi questionado na justiça desde que foi proposto, por ter ferido preceitos do Direito Ambiental e não visar o desenvolvimento sustentável. Além disso, as obras se iniciaram sem a realização de audiências públicas, o que foi motivo para a mobilização de protestos contra a realização da transposição, e o principal ponto colocado nos movimentos era que o projeto possuía o real intuito de beneficiar o agronegócio e não a população em si (HENKES, 2014). Mas, em 2005, o Conselho Nacional de Recursos Hídricos aprovou a realização da transposição.

Para que a transposição fosse aprovada, foi realizado o Estudo de Impacto Ambiental (EIA/RIMA) em que foram levantadas as possíveis consequências decorrentes da obra. De acordo com o Relatório de Impactos Ambientais (RIMA, 2004) foram identificados 44 impactos relacionados à implementação do projeto, sendo 23 de maior relevância; desses 11 são positivos e 12 negativos. Nosso objetivo é analisar a veracidade dos impactos citados no RIMA, com base em demais pesquisas e análises já publicadas. 


\section{Análise dos impactos}

Segundo Azevedo (2012), é impossível a realização de projetos de transposição de água sem impactos. Logo, é importante que os impactos causados por um projeto de tamanha dimensão sejam avaliados com cautela, visto que existem casos onde a interferência humana no curso de rios levou a desastres ambientais, como impactos na ictiofauna (MOREIRA FILHO; BUCKUP, 2005; BLANCO et al., 2010), proliferação de doenças (FAVRE et al., 2016), aumento da salinidade, redução do volume e até mesmo seca do rio, como o ocorrido no emblemático caso do Mar de Aral, onde a biodiversidade foi dizimada e o rio desertificou (MICKLIN, 2007). A ausência de estudos e descaso dos órgãos responsáveis colaboram para o agravamento dos impactos negativos (MOREIRA FILHO, 2006).

Além disso, as mudanças climáticas podem afetar a previsão dos impactos de projetos de transposição, o que exige maiores estudos e precisão no design, planejamento e estágios de operação de tais projetos. Devido a esse fator, as estratégias da transposição podem não funcionar, sendo falha a transferência de água em um futuro próximo (ZHANG et al., 2014). Portanto, a avaliação dos impactos causados pela Transposição do São Francisco e análises mais precisas sobre o real potencial de abastecimento são importantes de serem feitos.

\section{Impactos na fauna}

Segundo o Estudo de Impactos Ambientais (EIA), tanto as aves quanto os mamíferos estão sujeitos à caça para subsistência nas áreas de escassez hídrica devido à dificuldade de realizar práticas agrícolas. Por isso, eles consideram a transposição um fator positivo para a fauna. É relatado também que anfíbios dependem da água para sobreviver, portanto a transposição seria benéfica. $\mathrm{O}$ estudo também observou a existência de espécies exóticas de peixes, e alegou que a ictiofauna da região já foi muito prejudicada pela introdução de tais espécies, pela construção de açudes e pela redução da mata às margens do rio.

Contudo, há estudos que mostram que o abate de fauna se dá como medida preventiva aos ataques. A população local vê as espécies de mamíferos, répteis e aves como potenciais ameaças, na visão deles os animais silvestres representam riscos ou podem causar prejuízos (MENDONÇA et al., 2011). Ou seja, por mais que o EIA considere a transposição positiva para a diminuição da caça, não significa necessariamente que a população vai parar de caçar, uma vez que a caça pode ocorrer devido ao medo das espécies silvestres. 
No impacto 27- Modificação da composição das comunidades biológicas aquáticas nativas das bacias receptoras é proposta, como medida de prevenção à mudança nas comunidades aquáticas, a instalação de um filtro que impediria a passagem das espécies entre os locais de transposição. Todavia, já há artigos comprovando a mudança na biota aquática nos canais de transposição, como a invasão pelo molusco Limnoperna fortunei (DUNKER, 1857) (BARBOSA et al., 2016), mudanças em peixes do gênero Hoplias (BLANCO et al., 2010), aumento de moluscos transmissores de doenças (FAVRE et al., 2016). Assim, a medida proposta no RIMA não foi bem-sucedida.

\section{Disponibilidade de água potável}

Apesar da finalidade do projeto ser disponibilizar água para a população consumir, a água da transposição não será necessariamente potável, e sim contaminada com poluição ou com água salobra, dependendo de tratamento para ser ingerida (AB'SABER, 2006). No RIMA, os impactos 16- Aumento da oferta e da garantia hídrica; 17- Aumento da oferta de água para abastecimento urbano; 18- Abastecimento de água das populações rurais e 19- Redução da exposição da população a situações emergenciais de seca, preveem que a transposição ajudará na redução da seca. Esses quatro impactos positivos não citam se haverá estrutura de tratamento da água, e, caso não haja tratamento, seu consumo em alguns pontos será inviável.

Castro (2011), concorda com nosso argumento: para que os impactos 17 e 18 sejam eficientes, é preciso que haja tratamento de água. O mesmo autor alega que, no impacto 16, o aumento da oferta hídrica só será efetivado caso sejam construídas adutoras e canais para transportar a água para os usuários finais. E para que o impacto 19 se concretize, também dependerá de investimentos na infraestrutura de distribuição. Ainda de acordo com Ab'saber (2005), as águas que serão transportadas pelos canais poderão evaporar, visto que atravessarão a caatinga, onde o índice de evaporação é o maior de todos os biomas, podendo não chegar em seu destino com volume suficiente para a irrigação, abastecimento e consumo humano, ou seja, há também a necessidade de investimento para que isso não ocorra.

\section{Saúde}

A falta de tratamento da água fere também o impacto 22- Redução da exposição da população a doenças e óbitos, onde está escrito: “A oferta constante de água de boa qualidade 
contribuirá para a redução do número de internações hospitalares”. Se a água presente não for de boa qualidade, este impacto positivo é inválido.

Além disso, de acordo com Barbosa (2014), se não houver um projeto de conservação de bacias hidrográficas, diversos problemas sociais e ambientais podem ser ocasionados, devido ao lançamento de resíduos industriais, domésticos e assoreamento, também concordando com nosso argumento de que o impacto 22 será ferido. Segundo Silva et al. (2017), o esgoto foi canalizado para que não entre em contato com as galerias de água, porém acaba por desembocar dentro do rio, em um local onde a obra já foi finalizada. Logo, o projeto de transposição precisa ser acompanhado de melhorias no saneamento básico, pois a região receptora de águas da transposição não apresenta bons índices de saneamento.

De acordo com Favre et al. (2016), houve aumento nos casos de hospedeiros intermediários da esquistossomose na região da transposição, o que pode levar ao aumento do número de casos da doença. No impacto 6- Aumento e/ ou aparecimento de doenças, eles preveem o possível aumento dessa doença, e uma das medidas é monitorar os casos, como realmente tem sido feito, sendo possível visualizar no site do Ministério da Saúde (http://tabnet.datasus.gov.br/cgi/deftohtm.exe?sinan/pce/cnv/pcebr.def). Porém, demais medidas precisam ser tomadas para reduzir a propagação da doença, como, por exemplo, programas de conscientização para a população sobre a importância da higiene básica ou controle biológico das populações de caramujo.

Já o impacto 7- Aumento da demanda por infraestrutura de saúde, previa o possível aumento de casos de doenças durante a fase de construção, ou seja, já eram previstos os possíveis danos do projeto de transposição à saúde humana, apesar de ser somente na fase de construção, podemos considerar o impacto 7 como um impacto significativo, visto que o período de construção é longo. Para minimizar tais problemas, foram adotadas duas medidas: “implementar convênios com a Fundação Nacional de Saúde (Funasa) para agilizar a identificação e notificação de eventuais casos" e "monitorar a capacidade dos serviços de saúde locais" (RIMA, 2004). Apesar do relatório apresentar tais medidas que tratam de recuperar a saúde das pessoas caso sejam afetadas pela construção, ainda ocorre a violação do direito à saúde.

Segundo Ramos (2010), saúde não significa somente a recuperação de um indivíduo, engloba também a prevenção, ou seja, a redução do risco de doenças, e isso se dá a partir de ações coletivas. Então, a partir do momento que se assume que há a possibilidade do aumento 
de doenças na população, e nenhuma medida preventiva é tomada, ou menos planejada, ocorre a violação de um direito de todo ser humano, segundo o Art. 196 da Constituição Federal:

A saúde é direito de todos e dever do Estado, garantido mediante políticas sociais e econômicas que visem à redução do risco de doença e de outros agravos e ao acesso universal e igualitário às ações e serviços para a sua promoção, proteção e recuperação (BRASIL, 1988).

\section{Solo}

Problemas relacionados à erosão dos solos poderiam ser gerados pelas obras do projeto, como já previsto no impacto 35, que diz: "Início ou aceleração de processos erosivos e carreamento de sedimentos" (RIMA, 2004). Isso se dá devido às escavações para a abertura dos canais, túneis e estradas necessárias para a obra. No RIMA (2004) são citadas algumas medidas para reduzir esses impactos, porém, segundo Lima (2003), tais ações só serão eficientes em regiões que não estão sofrendo desertificação, o que é uma realidade em diversas áreas do Semiárido do Nordeste.

De acordo com o mesmo autor, os canais passam por várias áreas desertificadas que possuem o solo pobre em nutrientes, impossibilitando o plantio de espécies nativas, o que é uma das principais medidas que seria tomada pelo governo. Logo, o solo ficará exposto, aumentando os riscos de deslizamento e impedindo a recuperação da paisagem, o que contradiz as medidas apresentadas no RIMA - "cobrir as laterais das escavações com espécies nativas da região, de modo a reter a terra e evitar a formação de sulcos" e "monitorar áreas com maiores probabilidades de desmoronamento de pedras ou terra, numa ação preventiva para conter acidentes" -, a fim de minimizar os impactos da transposição do Rio São Francisco.

\section{Perda de vegetação nativa}

Com relação ao impacto 24, supostamente ocorreria perda e fragmentação de 430 hectares de áreas com vegetação nativa e de habitats de fauna terrestre, contudo, de acordo com Castro (2011), uma área muito maior seria impactada. Segundo o autor, essa estimativa foi subdimensionada, pois uma faixa $2,5 \mathrm{~km}$ ao longo dos canais foi declarada utilidade pública, e grande parte da vegetação ali presente pode ser perdida para trabalhadores rurais, ou seja, para 
assentamento. A área atingida realmente por construções, pelos canais e reservatórios correspondem a $200 \mathrm{~km}^{2}$ aproximadamente (CASTRO, 2011).

Além disso, o governo diz que a perda da vegetação - com a suposta perda e fragmentação de 430 hectares - é pequena em relação ao todo. Porém, não estão considerando que esse fator pode levar ao agravamento dos problemas de desertificação (LIMA, 2003), e, de acordo com Castro (2011), esse desmatamento seria muito maior que o previsto. Os problemas de desertificação, e consequentemente erosão dos solos, também serão muito maiores.

\section{Conclusão}

Podemos observar que nem sempre o planejado em projetos é executado da mesma forma, pois há inúmeras variáveis que interferem na execução deles, podendo até mesmo impactos positivos se tornarem negativos. A execução passa por inúmeras interferências durante o seu processo, o que torna o resultado diferente do que foi proposto, justamente devido à distância entre o que foi formulado e o que realmente está sendo posto em ação.

A justificativa para a transposição, que é possibilitar água nas áreas mais secas, pode até mesmo não se cumprir caso não sejam tomadas medidas em conjunto com o projeto. A melhoria na saúde pode se tornar uma piora, devido à falta de tratamento da água e aumento de hospedeiros de doenças, ou devido à falta de tratamento de esgoto. A redução do abate de vida silvestre pode não vir a ocorrer, o desmatamento pode ser maior do que o esperado, a erosão pode não ser solucionada com as medidas propostas, dentre outros problemas.

Em geral, o Estudo de Impactos não abrange totalmente os problemas que serão gerados, havendo falta de medidas em diversas áreas, ou medidas falhas. Além de incluir menos impactos do que causará. Portanto, é importante que estejamos atentos aos demais impactos que serão causados pela transposição, para que os problemas não sejam maiores que a possível solução. 


\section{Referências bibliográficas}

AB'SABER, A. A quem serve a transposição? Folha de S. Paulo, São Paulo. 2005. p.A18. Disponível em: https://sttrdeangicos.blogspot.com/2013/01/a-quem-serve-transposicao-dosao.html Acesso em: 20 jun 2019.

AB'SABER, A. A transposição de águas do São Francisco: análise crítica. Revista USP, v.LXX, p. 6-13, 2006.

AZEVEDO, L.G.T. Integração de Bacias Hidrográficas. In: ANA, Agência Nacional de Águas. A Questão da Água no Nordeste. Brasília: CGEE, 2012. p.333-372.

BARBOSA, F. A. P. Degradação ambiental a partir da transposição do Rio São Francisco no eixo leste na cidade de Monteiro-PB. Guarabira: UEPB, 2014.

BARBOSA, N. P. U.; SILVA, F. A.; OLIVEIRA, M. D. de; SANTOS NETO, M. A. dos; CARVALHO, M. D. de; CARDOSO, A. V. Limnoperna fortunei (Dunker, 1857) (Mollusca, Bivalvia, Mytilidae): first record in the São Francisco River basin, Brazil. Check List, v.XII p.16, 2016.

BLANCO, D. R.; LUI, R. L.; BERTOLlO, L. A. C.; DINIZ, D.; FILHO, O. M. Characterization of invasive fish species in a river transposition region: evolutionary chromosome studies in the genus Hoplias (Characiformes, Erythrinidae). Rev Fish Biol Fisheries, v.XX, 2010.

BRASIL. Constituição da República Federativa do Brasil de 1988. Brasília: Presidência da República. Disponível em: http://www.planalto.gov.br/ccivil_03/Constituicao/ Constituiçao.htm. Acesso em: 12 set 2019.

CASTRO, C. N. Transposição do Rio São Francisco: Análise de Oportunidade do Projeto. Rio de Janeiro: Ipea, 2011.

FAVRE, T. C.; FERNANDEZ, M. A.; BECK, L. C. N. H.; GUIMARÃES, R. J. de P. S.; PIERI, O. S.; THIENGO, S. A. C. Assessment of schistosomiasis in the semi-arid Northeast region of Brazil: the São Francisco River large-scale water transposition project. Revista da Sociedade Brasileira de Medicina Tropical, v.XLIX, p.252-257, 2016.

GOMES, G. M. Velhas secas em novos sertões. Brasília: Ipea, 2001.

HENKES, S. L. A política, o direito e o desenvolvimento: um estudo sobre a transposição do rio São Francisco. Revista Direito GV, v.X, p.497, 2014.

MARENGO, J. A., ALVES, L. M., BESERRA, E. A., LACERDA, F. F. Variabilidade e mudanças climáticas no semiárido brasileiro. Campina Grande: Instituto Nacional do Semiárido, 2011. 
MENDONÇA, L. E. T.; SOUTO, C. M.; ANDRELINO L. L.; SOUTO W. M. S.; VIEIRA W. L. S.; ALVES R. R. N. Conflitos entre pessoas e animais silvestres no Semiárido paraibano e suas implicações para conservação. Sitientibus série Ciências Biológicas, v.XI, p.185-99, 2011.

MICKLIN, P. The Aral Sea Disaster. Annual Review of Earth and Planetary Sciences, v.XXXV, p.47-72, 2007.

MINISTÉRIO DO DESENVOLVIMENTO REGIONAL. Projeto Rio São Francisco: Mudanças em sua vida - Benefícios. 2019. Disponível em http://www.mdr.gov.br/projeto-riosao-francisco/a-mudanca-em-sua-vida/beneficios Acesso em: 2 jun 2019.

Projeto Rio São Francisco: Meio Ambiente preservado - O Rio e seus Números. 2019. Disponível em http://www.mdr.gov.br/projeto-rio-sao-francisco/meio-ambiente-preservado Acesso em: 2 jun 2019.

MOREIRA FILHO, O.; BUCKUP, P. A. A poorly known case of watershed transposition between the São Francisco and upper Paraná river basins. Neotrop. Ichthyol, v.III, p.449-452, 2005.

MOREIRA FILHO, O. Uma transposição de rio esquecida. Revista UFG, v.VIII, p.1-4, 2006. LIMA, T. V. P. C. Os impactos da transposição do rio São Francisco na sua região de influência. Brasília: Universidade de Brasília, 2013.

RAMOS, M. C. S. O direito fundamental à saúde na perspectiva da constituição federal: uma análise comparada. Revista Jurídica da Procuradoria Geral do Estado do Paraná, v. I, p.5392, 2010.

RIMA. Projeto de Integração do Rio São Francisco com Bacias Hidrográficas do Nordeste Setentrional. Ministério da Integração Nacional. 2004. Disponível em http://www.mi.gov.br/images/stories/ProjetoRioSaoFrancisco/ArquivosPDF/documentostecni cos/RIMAJULHO2004.pdf Acesso em: 10 jan 2019.

SILVA, A. P.; PEREIRA, J. A. V.; SANTOS, J. S.; SILVA, E. F. B. Impactos Socioambientais e a Transposição do Rio São Francisco: um olhar sobre o Eixo Leste. Anais... III workshop internacional sobre água no semiárido brasileiro, v.1, 2017.

ZHANG, C.; ZHU, X.; FU, G.; ZHOU, H.; WANG, H. The impacts of climate change on water diversion strategies for a water deficit reservoir. Journal of Hydroinformatics, v.XVI, p.87289, 2014. 